U. S. DEPARTMENT OF COMMERCE HARRY L. HOPKINS, Secretary

NATIONAL BUREAU OF STANDARDS

LYMAN J. BRIGGS, Director

Bureav of standimu

JUL COMMERCIAL STANDARDS AND

THEIR VALUE TO BUSINESS

(THIRD EDITION)

COMMERCIAL STANDARD CS0-40

(Supersedes CSO-39)

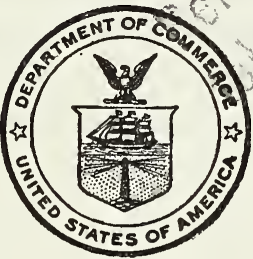

RECORDED VOLUNTARY STANDARDS

OF THE TRADE

UNITED STATES

GOVERNMENT PRINTING OFFICE

WASHINGTON : 1940 
"Wherever we find great work being done in music, art, or science, amid the infinite diversity of creative expression we discover, at the core and center, standards concerning which men are sure that their betrayal never can be right nor their observance wrong."

Harry Emerson Fosdick. 


\section{FOREWORD}

We need only glance at the rich background of standards in nature to gain perspective and obtain a better appreciation of present trends in standardization and their significance. In the same species of plants, fishes, birds, or animals, individuals resemble each other in the minutest detail of structure and function. So thorough has nature been that every species may be recognized by the standardized organs, functions, characteristics, or habits peculiar to each. At the same time, individuals exhibit definite distinguishing characteristics and develop in diverse directions to stimulate the natural processes of selection, survival, and evolution.

The more the mysteries of nature are dispelled by knowledge, the more is standardization revealed, as in the geometrical arrangement of crystal formation, predicted discoveries of new chemical elements, or the coming of a comet. We depend upon the meticulous regularity of the sun's appearance, the recurring phases of the moon, and the perfectly timed rotation of the planets. We accept as indisputable facts the definitely established boiling and freezing points, the peculiar behavior of certain materials and the changeless normal properties of elasticity, strength, hardness, ductility, viscosity, refractivity, electric conductivity, permeability, and other properties of the elemental things of nature which man is constantly appropriating for his use.

The variations of color available to the painter are composed of parts of a narrow band of spectral wave lengths and all of the artistry in music is conveyed through another small group of frequencies. And yet we hear no complaints that nature has carried standardization to extremes, that life is dull, drab, or dreary as a result of standardized chemical elements, standardized crystalline growth, or wave lengths, as in sound, radio, light, and X-rays.

In every direction we find standardization, whether we look to the orbits of the electrons about the atom, the constellations of the stars, the microcosm or the macrocosm, industry or sport, commerce or the arts.

The architect may be limited to one size of common brick but he has a choice of color, texture, and arrangement sufficient to produce an umlimited variety of structures and effects, while the accomplished limitation of dimensions gives him a basis upon which to start and relieves his mind altogether of the problem of the size of brick to be employed.

The need for a wider application and use of voluntary standards developed and approved so as to merit national recognition has long been appreciated. To assist in securing this result in line with its authorized functions, the National Bureau of Standards inaugurated in 1927 a procedure under which voluntary standards, properly adjusted and accepted, are printed as official publications of the Department of Commerce and promulgated as "Commercial Standards."

Lyman J. Briggs, Director. 



\title{
COMMERCIAL STANDARDS AND THEIR VALUE TO BUSINESS
}

\author{
(Third Edition)
}

Note.-Those who prefer the question and answer style for a quick grasp of the main features of the commercial standards service may turn directly to page 18.

\section{BACKGROUND AND PURPOSE}

\section{DEFINITION OF STANDARDS}

1. Community life in ancient times was governed and advanced by customs and rules which constituted the first standards, such as, speech, symbol and picture writing, clothing, shelter, family, religion, time, and barter. The earliest known systems of weights and measures were those of the Assyrians, Babylonians, Chaldeans, and Egyptians. The English system of weights and measures may be traced to the early Saxons.

2. It is interesting to note that one of the first recommendations which the first President of the United States, George Washington, made to the first Congress, January 1790, stated "Uniformity in the currency, weights, and measures of the United States is an object of great importance and will, I am persuaded, be duly attended to."

3. To many people the word "standard" connotes something carefully established by man, as a compulsory unit of weight, measure, or coinage. According to Funk and Wagnall's New Standard Dictionary the noun is defined as follows:

Standard, 1. Any measure of extent, quantity, quality, or value established by law or by general usage and consent; a weight, vessel, instrument, or device sanctioned or used as a definite unit as of value, dimension, time, or quality, by reference to which other measuring instruments may be constructed and tested or regulated.

2. Hence, any type, model, example, or authority, with which comparisons may be made; any fact, thing, or circumstance forming a basis for adjustment and regulation; a criterion of excellence; test; ***.

4. In outlining the functions of the National Bureau of Standards, the first Secretary of Commerce, the Honorable William C. Redfield, incorporated in his annual reports (beginning in 1915) five classes of standards and their respective purposes which still hold. Classes 1 and 2 are Standards of Measurement and Standard Constants, respectively. Class 3, Standards of Quality, fix in measurable terms, a property or group of properties which determine the quality, to secure high utility in the products of industry by setting an attainable standard of quality; to furnish a scientific basis for fair dealing to avoid disputes or settle differences; to promote truthful branding and advertising by suitable standards, and methods of test; to promote precision and avoid waste in science and industry by affording quality standards by which materials may be made, sold, and tested. 
Class 4, Standards of Performance, specify the factors involved in terms susceptible of measurement, to clarify the understanding between maker, seller, buyer, and user as to operative efficiency of appliances and machines; to make exact knowledge the basis of the buyer's choice; to stimulate and measure mechanical progress. His fifth class deals with standards of practice.

5. We are concerned here not with compulsory standards established by law or authority, but with voluntary standards set up by common consent.

\section{COMMERCIAL STANDARDS}

6. In this day of unprecedented variety and complexity of commodities the buyer, whether acting for a large corporation, a department store, or a single family, is confronted with a bewildering variety of product, clever claims, and adulant advertising, which are difficult to evaluate. How can he compare quality or value with any degree of safety or assurance? Whether he plans to purchase a tank car of fuel oil or a clinical thermometer, where and what is the yardstick for quality?

7. The producer is continually puzzled to keep his good ship on a safe course away from the torpedoes of cut price and lowered quality. How can a steady business be built up which will carry through periods of depression on assured market and stable values?

8. The great competition today is between industries, and it is natural, therefore, that members of a given industry should desire to set up one or more minimum quality levels for their commodity in order that the public may buy with assurance and confidence and that the commodity as a whole shall retain the good will, and command the respect, of the purchaser. When there is a standard for rating hidden characteristics, established in a way to command respect, accepted and recognized by producers and consumers alike, readily available, and regularly used as a basis for daily trade it naturally becomes the yardstick for the invisible or complex elements of quality for that commodity. This can be arranged quite effectively through the establishment of commercial standards.

\section{DEFINITION OF COMMERCIAL STANDARDS}

9. Commercial standards promulgated by the National Bureau of Standards are voluntary recorded standards agreed upon by producers, distributors, and consumers, covering terminology, types, classifications, grades, sizes, and use characteristics of manufactured products as a basis for better understanding between buyer and seller. They include standard methods of test, rating, certification, and labeling, and provide a uniform basis for fair competition. They are made effective by means of voluntary guarantees on invoices, on labels, or by grade marks on the goods themselves.

\section{ECONOMIC NECESSITY}

10. In the present perplexing market of novelties and synthetics, the consumer-buyers, and even the professional purchasing agents, are reporting it increasingly difficult to distinguish between items of real merit and inferior products built for appearance only. It is natural, therefore, that both are seeking authoritative and dependable 
criteria of quality, and are welcoming certificates from reputable producers that the quality of the goods equals or exceeds the commercial standard specification.

11. Among the producers, competition was never keener. In the ever-widening arena of strife for a share of the consumer's dollar, companies are merging and individual producers are forming associations to wage the contest of industry against industry as being more significant than the private battle of producer against producer. The alert trade association seeks a means of assuring purchasers of the inherent quality of the proffered goods. Individual trade-marks and trade association labels are helpful, but frequently are not sufficient to satisfy the skepticism of the modern purchaser who demands to be shown, with laboratory analyses and methods of test, the quality of goods delivered. In general, it may be said that the producers are experts in their own commodity field, but seldom is the consumer given the full benefit of this knowledge. Usually the producers as a group could, if they would, inform the consumer as to the grade or quality best suited to his needs with greater accuracy and confidence than the consumer could muster from any other source. Under present conditions this group knowledge often is suppressed and the tendency is all too frequent to give the buyer merely what he requests.

\section{SCOPE}

12. The most significant restriction is the present limitation of commercial standards to commodities which are bought and sold; that is, commercial standards have not been applied to safety codes, drafting-room practices, symbols, methods of test as such, or trade practices. Rather, commercial standards consist of specifications, nomenclature, definitions, grading rules, dimensional requirements, and tests as a means of determining and checking the hidden quality of goods constituting the life blood of trade. Commercial standards by nature are a compromise of the ideas held by representatives of producers, distributors, and consumers and may not be expected to represent perfection. However, they constitute a step in the right direction, and successive revisions bring them closer to the ideal specification setting forth clearly the requirements desired by the user, checked by recognized tests, without restricting the ingenuity of the producer in the employment of new materials, processes, or methods.

\section{PURPOSE}

13. The chief purpose of the work is to catch and to hold from present or future retrogression, commercial progress toward ideals of commodity quality and performance by encouraging the voluntary establishment of commercial standards as a basis for marketing, inspection, testing, acceptance, or rejection. It is unthinkable that the consumer will willingly relinquish nationally recognized means and methods of checking the quality and value of the goods he buys. Therefore, it is hoped that the commercial standard will act as a ratchet in the advance of sound marketing methods.

14. The service is mainly coordinational in character, since its chief missions are to hold conferences on a standard or a specification which any group may want to promulgate on a Nation-wide basis; to determine its eligibility for promulgation; to publish and broadcast it in the event the prerequisites of procedure have been met, including a 
satisfactory majority acceptance; to facilitate direct labeling for the assurance and convenience of the small purchaser or over-the-counter buyer; to provide means for periodical audits of adherence; and otherwise to accelerate the effective use of standards as a basis for daily transactions.

\section{FUNCTION OF THE DIVISION OF TRADE STANDARDS}

15. The function of the Division of Trade Standards in work of this character is fourfold: First, to act as an unbiased coordinator to insure adequate consideration of the needs of all interests and the mutually satisfactory adjustment of trade standards; second, to supply such assistance and advice in the development of this program as past experience with similar programs may suggest; third, to canvass and record the extent of acceptance and adherence to the standard on the part of producers, distributors, and users; and fourth, after acceptance, to publish and promulgate the standard for the information and guidance of buyers and sellers of the commodity. The Division also acts as a clearing house for directing suggested standardization projects into the proper channels, to avoid duplication of effort, and to correlate parallel plans.

\section{PROCEDURE}

\section{THE INITIATION OF A COMMERCIAL STANDARDS PROJECT}

16. The request for cooperation usually comes from a group of producers, distributors, or consumers sufficiently interested in the commodity to put forth some effort in its behalf. Any interested group may request the cooperation of the National Bureau of Standards in the establishment of a commercial standard. It is not necessary that the request come from an association or other organization, although experience indicates that standards sponsored by such organizations are more likely to be finally accepted than those proposed by single companies or individuals. The assistance and support of a trade organization is of great value later in making the certification and labeling work effective. In initiating the work the proponent group is expected to assume certain responsibilities, such as the selection of the specification, the preparation of the tentative draft, attending preliminary conferences, supplying data, information, or advice as the situation may require. The Bureau makes no charge for its part in establishing commercial standards, since they serve and benefit producers, distributors, and consumers alike.

17. Upon receipt of the written request for cooperation, the subject is assigned to a "project manager," who represents the National Bureau of Standards in contacts with those directly concerned throughout the development of the project and is responsible for the proper conduct of the work. It is the duty of the project manager to seek out any broadly accepted specifications or standards relevant to the subject and report to the proponent group, emphasizing the advantages of adopting an existing standard wherever practicable.

\section{PRELIMINARY SURVEY}

18. In the event pertinent data are lacking, the project manager, through the proponent group, conducts a preliminary survey of all available standards, those in process of formulation, and existing 
methods of test. This survey may also cover production figures, sales records of various types, grades, classes, finishes, colors, or other data pertinent to the project.

\section{SELECTION OR FORMULATION OF THE SPECIFICATION}

19. From the above data the proponent group selects or formulates a tentatively satisfactory specification as a starting point for further action. This may take the form of minimum measurements, tolerances, construction, chemical composition, physical requirements, or method of manufacture, in the event it is not practicable to specify and test on a performance basis. The latter is generally preferable where test methods simulate conditions of use.

\section{PRELIMINARY CONFERENCE}

20. After a tentatively satisfactory specification has been selected or formulated, a preliminary conference of leading members (all of the members when the group is small) of the proponent group is called to consider the acceptability of the specification from the point of view of the purchasers, distributors, or producers, as the case may be, and the probable reaction of the other interested branches of the industry.

21. It may be best to repeat that the proponent group is usually limited to one branch of business-producers, distributors, or consumers-thus facilitating action and helping to correlate and to epitomize the desires of the group most eager to establish a commercial standard. This method tends to promote free and frank discussion of all ramifications of the standard and thus produces a firm foundation for subsequent discussion, acceptance, certification, and labeling.

22. The preliminary conference is usually held under the auspices of the National Bureau of Standards so as to admit both members and nonmembers of organizations in the field. It is sometimes necessary to hold several preliminary conferences, to appoint subcommittees, or to refer the entire subject to a technical society for formulation, as it has been found particularly advisable to have at least the proponent group substantially in harmony before calling a general conference of all interests.

\section{TECHNICAL REVIEW AND ADJUSTMENT}

23. Acting upon the recommendations of the preliminary conference or the survey committee, agenda are prepared for a general conference of producers, distributors, organized consumers, and allied interests. Said agenda are then referred to interested national organizations and to the proper technical division of the National Bureau of Standards for review to insure compatibility with the trend of the most recent research and development in the art, with recommendations resulting from research or tests, as well as recommendations supported by various technical societies. When this review has been completed and such adjustments made as circumstances may warrant, the agenda are then submitted to the proponent group for review and authorization to call a general conference of all interests (public hearing). 


\section{GENERAL CONFERENCE-ADJUSTMENT AND ADOPTION}

24. Following such authorization, the National Bureau of Standards forwards the agenda, including the proposed commercial standard, to all known manufacturers, distributors, organized consumers, and other interested organizations with an invitation to attend a conference at a specific time and place, frequently Washington, D. C. Frank criticism of the proposed standard is invited for presentation either in writing or in person at the general conference. This general conference, or public hearing, considers what action is feasible and desirable regarding further adjustment, application, and broader promulgation of the recommended standard, and votes to establish it, with any necessary modifications, as a "recommended commercial standard." It also appoints representative members of interested groups to act as a standing committee to pass upon proposed revisions which may be submitted in the future, before circulating such revisions for written acceptance. A typical order of procedure is shown graphically in the chart. (Fig. 2.)

\section{WRITTEN ACCEPTANCE}

25. Oral approval at the general conference is considered an insufficient authorization for publication as it is frequently necessary for a member of that conference to sell the idea to the other officers of his organization before they recognize the benefits of adopting the commercial standard as a regular practice. It is also desired that no such fundamental changes in policy and marketing methods be established hurriedly or without due and careful deliberation by business executives in the atmosphere of their own offices. Therefore, the National Bureau of Standards disseminates the recommendations of the general conference with an opportunity for written acceptances from all interested groups, including manufacturers, distributors, organized consumers, and testing laboratories.

26. A sample acceptance form is shown on page 9. The explanatory statement, which appears on the reverse side of the acceptance blank, is shown on page 10 .

\section{LABELING}

27. Manufacturers are encouraged to apply self-certifying labels, such as illustrated in figure 1, to the commodity guaranteeing the quality or measurements to conform to all requirements and tests of the commercial standard. In the event the goods are of such a nature as to inhibit the direct use of "guarantee" labels, a registered symbol may be employed as a certification of quality when supported by full "guarantee" labels on the cartons or other container in which the commodity is delivered to the consumer.

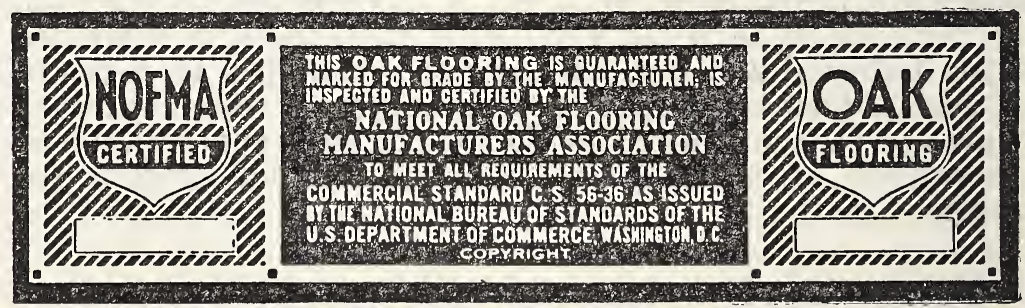

FIGURE 1.-Oak flooring label. 


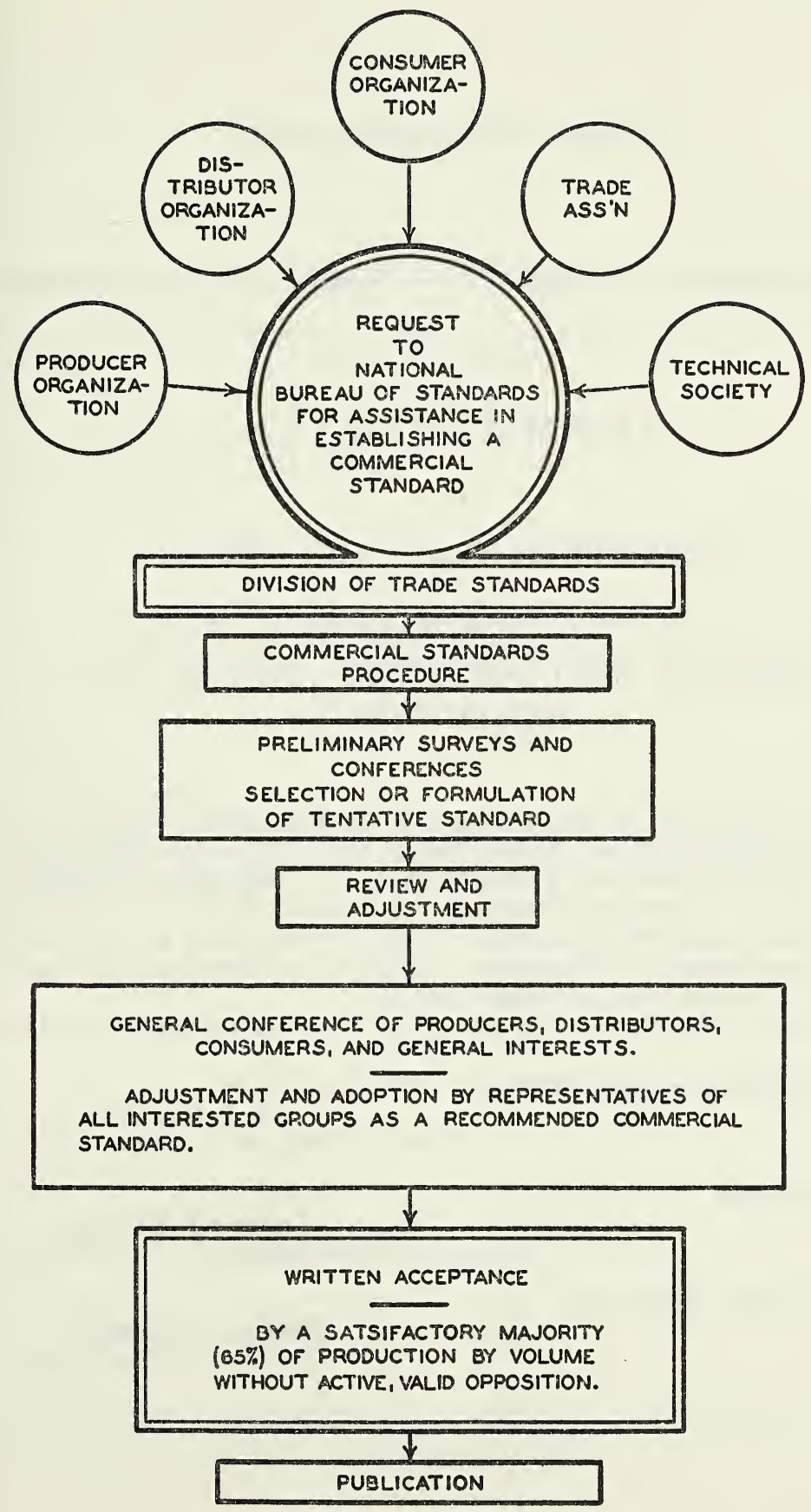

Figure 2.-Typical development of a commercial standard. 


\section{PROMULGATION}

of

COMMERCIAL STANDARD CS78-39

for

\section{GROUND AND POLISHED LENSES FOR SUN GLASSES}

On June 16, 1939, at the instance of the Sun Glass Institute, Inc., a general conference of representative manufacturers, distributors, and users of ground and polished lenses for sun glasses adopted a recommended commercial standard for this commodity. The industry has since accepted and approved for promulgation by the United States Department of Commerce, through the National Bureau of Standards, the standard as shown herein.

The standard is effective for new production from October 10, 1939.

Promulgation recommended.

I. J. Fairchild, Chief, Division of Trade Standards.

Promulgated.

Lyman J. Briggs, Director, National Bureau of Standards.

Promulgation approved. 


\section{ACCEPTANCE OF COMMERCIAL STANDARD}

This sheet properly filled in, signed, and returned will provide for the recording of your organization as an acceptor of this commercial standard.

Division of Trade Standards,

Date

National Bureau of Standards,

Washington, D. C.

\section{Gentlemen :}

Having considered the statements on the reverse side of this sheet, we accept the Commercial Standard CS67-38 as our standard of practice in the

Production ${ }^{1} \quad$ Distribution $^{1}$ Use ${ }^{1}$

of karat-gold articles.

We will assist in securing its general recognition and use, and will cooperate with the standing committee to effect revisions of the standard when necessary.

Signature

Name and title

Organization

(Fill in exactly as it should be listed in pamphlet)

Street address

City and State

1 Please designate which group you represent by drawing lines through the other two. Please file separate acceptances for all subsidiary companies and affiliates which should be listed separately as acceptors. In the case of related interests, trade papers, colleges, etc., desiring to record their general approval, the words "in principle" should be added after the signature. 


\section{TO THE ACCEPTOR}

The following statements answer the usual questions arising in connection with the acceptance and its significance:

1. Enforcement.-Commercial standards are commodity specifications voluntarily established by mutual consent of those concerned. They present a common basis of understanding between the producer, distributor, and consumer and should not be confused with any plan of governmental regulation or control. The United States Department of Commerce has no regulatory power in the enforcement of their provisions, but since they represent the will of the interested groups as a whole, their provisions through usage soon become established as trade customs, and are made effective through incorporation into sales contracts by means of labels, invoices, and the like.

2. The acceptor's responsibility. - The purpose of commercial standards is to establish for specific commodities, nationally recognized grades or consumer criteria and the benefits therefrom will be measurable in direct proportion to their general recognition and actual use. Instances will occur when it may be necessary to deviate from the standard and the signing of an acceptance does not preclude such departures; however, such signature indicates an intention to follow the commercial standard where practicable, in the production, distribution, or consumption of the article in question.

3. The Department's responsibility.-The major function performed by the Department of Commerce in the voluntary establishment of commercial standards on a Nation-wide basis is fourfold: first, to act as an unbiased coordinator to bring all interested parties together for the mutually satisfactory adjustment of trade standards; second, to supply such assistance and advice as past experience with similar programs may suggest; third, to canvass and record the extent of acceptance and adherence to the standard on the part of producers, distributors, and users; and fourth, after acceptance, to publish and promulgate the standard for the information and guidance of buyers and sellers of the commodity.

4. Announcement and promulgation.-When the standard has been endorsed by a satisfactory majority of production or consumption in the absence of active, valid opposition, the success of the project is announced. If, however, in the opinion of the standing committee or the Department of Commerce, the support of any standard is inadequate, the right is reserved to withhold promulgation and publication. 


\section{PUBLICATION}

28. On receipt of signed acceptances representing at least 65 percent of production or consumption by volume, and provided there is no outstanding or active, valid opposition, a circular letter then announces the success of the project and the date upon which the commercial standard becomes effective. At the same time the manuscript is prepared for printing by the Public Printer. Upon release of the publication, printed copies are distributed to all acceptors and to all who have cooperated in the work. Additional copies are made available at a very moderate price (usually 5 or $10 \cdot$ cents) with a discount of 25 percent in quantities of 100 or more, through the Superintendent of Documents, U. S. Government Printing Office, Washington, D. C.

\section{STANDING COMMITTEE AND REVISION}

29. The standing committee, appointed by the general conference, is responsible for carrying on the standardization of the product. This committee consists of members representing producers, distributors, consumers, and testing laboratories, and thus reflects the wellbalanced viewpoint of all concerned. The members of the committee receive all suggestions regarding the commercial standard and consider its revision in the event that such action is desirable and mutually beneficial. If the commercial standard does not require revision, it may be reaffirmed in its existing form, but if any important changes are found desirable, their adoption is recommended by the committee, whereupon all interested groups are again solicited for written acceptance of the standard in its revised form. The committee is, in effect, a centralizing agency for criticisms and comments regarding the commercial standard and is charged with the responsibility of recommending revisions to keep the standard abreast of current industrial practice. It also receives reports on departures from the commercial standard. The last two figures in the identification number assigned to each commercial standard signify the year in which it is made effective, thus distinguishing revisions from earlier issues.

\section{EXAMPLES OF COMMERCIAL STANDARDS}

\section{CLINICAL THERMOMETERS (SECOND EDITION)}

30. The manufacturers requested the National Bureau of Standards to assist them in setting up a standard to be used as a basis for sale and certification of reliable clinical thermometers. At a general conference of representatives of laboratories, manufacturers, distributors, and users of clinical thermometers, a commercial standard was adopted which surpassed in some respects the requirements of the Federal Government and many States and municipalities. The original standard became effective for new production October 1, 1928, and a revised and improved standard became effective June 1, 1932, after having been accepted by the principal users and producers. Printed copies may be obtained from the Superintendent of Documents, U. S. Government Printing Office, Washington, D. C.

31. A commercial standard clinical thermometer must comply with certain requirements definitely and completely set forth in Commercial Standard CS1-32. The requirements cover (a) construc- 
tion, in which quality of glass, appearance, marking, range, and details of graduation are specified; $(b)$ character of pigment, in which a test is required to determine the resistance of the pigment to removal by disinfecting solutions; $(c)$ test for entrapped gas; $(d)$ hard shaker test; (e) retreat test, to determine whether the constriction in the bore is properly made; $(f)$ accuracy, in which the maximum allowable errors in registration are specified with the method of determining them; $(g)$ ageing for four months, chiefly to guard against changes in the constriction; and $(h)$ a certificate as shown below which shall accompany each thermometer to guarantee compliance with the requirements. We, the undersigned manufacturers, hereby certify that our registering
clinical thermometer marked No. found to meet all of the requirements and tests specified in the United States Department of Commerce Commercial Standard CS1-32 for Clinical Thermometers.

(Company)

32. Each clinical thermometer is an individual instrument, requiring special graduation and subject to errors peculiar to itself because no adjustments can be made after sealing in the mercury. In order to guard against inaccurate and unreliable clinical thermometers, many institutions test every thermometer they use. Varying methods of testing and varying requirements of accuracy and construction were used. Manufacturers were not only required to make good the rejected thermometers, but considerable expense was involved in the diversified testing and marking for purchasers.

33. With the commercial standard as a basis the manufacturers are now able to produce thermometers that are acceptable to almost every user, and the signed certificates reduce the need for much of the testing by consumers. The commercial standard requirements are based on the proper normal use of a clinical thermometer; they may be readily met under appropriate conditions of manufacture, and form a definite and fair basis for competition.

\section{STODDARD SOLVENT (SECOND EDITION)}

34. Several years ago common motor gasoline was widely used for dry-cleaning purposes, fires were frequent, the garments thus cleaned retained objectionable odors, and many were damaged needlessly by the practice. Following technical investigations conducted by the National Association of Dyers and Cleaners at the National Bureau of Standards, a recommended specification for a comparatively safe dry-cleaning solvent was announced in May 1925. After a period of trial and suitable adjustments, the specification was accepted by the trade as a commercial standard effective March 1, 1928.

35. The product, known as Stoddard Solvent and marketed under many trade names, grew in popularity and commercial importance, and the standard was improved by a revision effective from February 10,1938 , identified as Commercial Standard CS3-38. The 10 specific requirements include color, odor, corrosive properties, flash point, distillation range, sulphuric acid absorption, and acidity. Today it constitutes the chief petroleum product used for dry-cleaning purposes; it is widely available; the standard provides a fair basis of competition; 
fires are virtually unknown; insurance rates are reduced; the consumer receives better work; and the market for the standard product has been broadened to include use in cleaning printing presses, type, machine, and auto parts, since it is safer and superior to gasoline for these purposes.

\section{BUILDERS' TEMPLATE HARDWARE}

36. The increasing use of hollow metal doors and trim has made necessary a wider application of the construction standards which their use entails. This need prompted the industry to request the National Bureau of Standards to assist in securing more general recognition of standards as well as to assist in the reconciliation and consolidation of a number of conflicting standards in use. The principal object is to facilitate the application of locks and hinges to hollow metal doors and frames, as provisions for attaching such fittings must be made in the process of manufacture. The Commercial Standard CS9-33 specifies the maximum and minimum dimensions of lock cases for hollow metal doors. Template dimensions and tolerances for the lock front and strike are given. Template dimensions for full-mortise, full-surface, half-mortise, and half-surface butts are included with template identification symbols, tolerances, and clearance for painting.

\section{FUEL OILS (FIFTH EDITION)}

37. Twelve years ago fuel oil was a burdensome byproduct of gasoline manufacture. Very little attention was given to its quality, and grading was chiefly on the basis of specific gravity. This property was found to have no direct bearing on adjustment to burner requirements.

38. Realizing that the more serious difficulties in the use of oil for fuel in automatic burners were due to inadequate grading, the American Oil Burner Association requested the establishment of a commercial standard covering standard grades that would enable the user always to obtain an oil suitable to his burner. With the cooperation of the American Society for Testing Materials and the American Petroleum Institute, requirements for six grades, three for domestic and three for industrial use, were formulated on the basis of distillation range and viscosity characteristics. This system of grading was accepted and established as Domestic and Industrial Fuel Oils, Commercial Standard CS12-29.

39. Since that time four revisions have been adopted and issued under the designations CS12-33, CS12-35, CS12-38, and CS12-40.

40. A steady improvement in quality is shown by these revisions. The present standard covers not only distillation and viscosity but other quality characteristics such as carbon residue, flash point, pour point, maximum water, sediment, and ash. Each grade is identified by a number for the convenience and assurance of all concerned in buying and selling fuel oils according to requirements of the commercial standard. The number of grades has been reduced to a total of five for both domestic and industrial use, and the industry looks forward to the possibility of fewer grades as the quality can be improved and as burners and refinery practices become more adequately standardized. 
41. Revisions are recommended by a standing committee of producers, distributors, and users, in cooperation with Technical Committee E of ASTM Committee D-2. This Society has also issued the specification, identical in substance with the commercial standard, under the designation D396-39T. The Underwriters' Laboratories, Inc., test burners for safety and issue lists of burners approved for use with oils not heavier than a specific commercial standard grade.

\section{WOOD SHINGLES (FOURTH EDITION)}

42. In the decade between 1920 and 1930, sharp competition from other roofing materials served only to intensify the competition between the manufacturers of red-cedar shingles. Many producers sought temporary advantage over their neighboring mills by reducing the thickness as well as the quality of their shingles. Vague grade designations were employed which misled the buyer, including such terms as "Extra Clear" for shingles containing defects that greatly reduced their efficacy as a satisfactory roofing material.

Label Series D 574
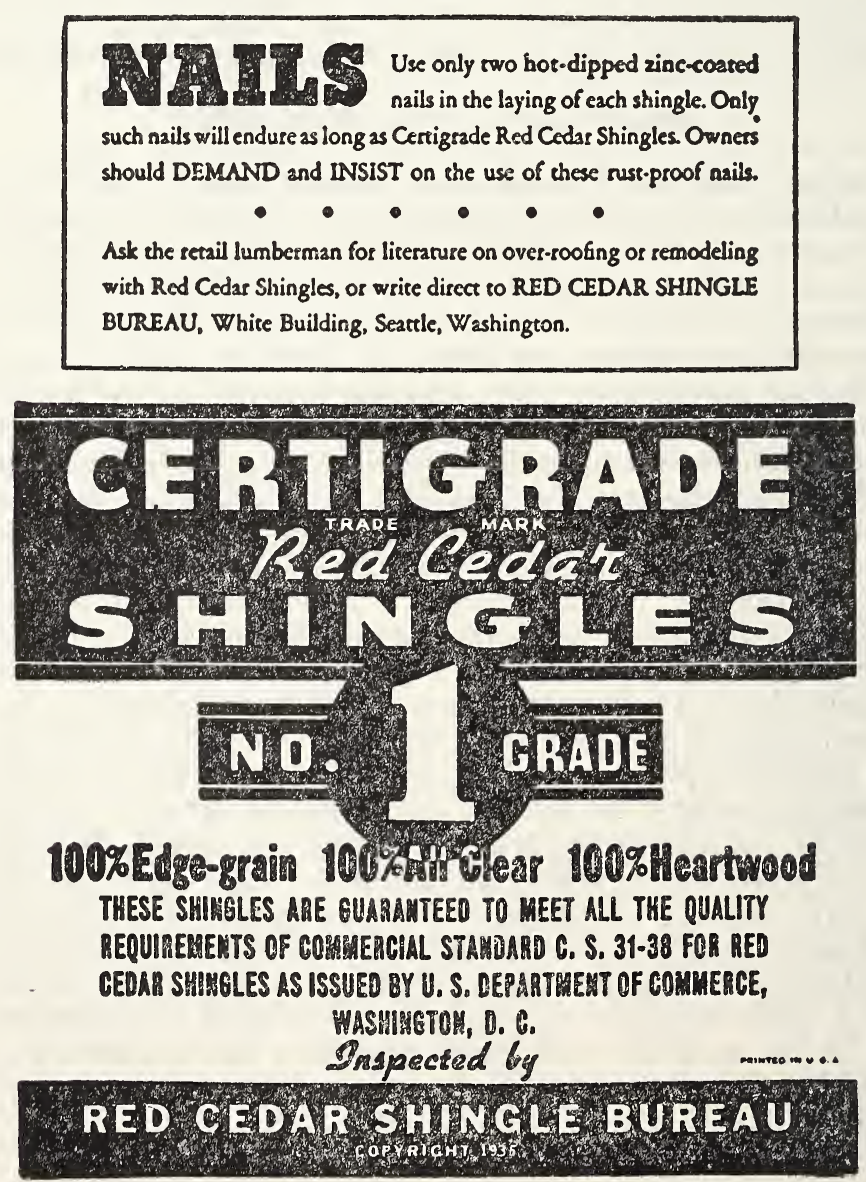

Figure 3.-Label for No. 1 grade shingles. 
43. In 1931 the industry under the leadership of the Red Cedar Shingle Bureau decided to concentrate promotional effort on the highest grade of shingle and to manufacture this product up to a "standard" rather than down to a price. Accordingly, following the necessary conferences and adjustments, the accepted specifications for No. 1 grade red-cedar shingles were promulgated by the National Bureau of Standards as Commercial Standard CS31-31, which standard was later extended to include shingles made of California redwood and Southern cypress. Improved by three successive revisions, the fourth edition of the standard is identified as CS31-38.

44. The quality of the product is certified by the producer and underwritten by the Association, by means of labels on each bundle, as illustrated in figure 3 . Rigid inspection service results in the maintenance of uniformly high quality, and the confusing grade designations have been voluntarily discarded.

45. The consumer has been definitely helped through the establishment of a firm, enforcible basis of quality, the distributor has benefited by the increased consumer and community acceptance of wood shingles, and the manufacturer, as in any satisfactory business relationship, has benefited by the favorable customer reaction.

\section{GOLD FILLED ARTICLES}

46. Prior to 1934 the mark "Gold Filled" on an article merely indicated a process of manufacture without any significance as to the quantity or proportion of gold applied. In this process a gold alloy of definite Karat fineness is silver soldered to base metal (largely copper) and then the whole is rolled or drawn to the required thickness. The resulting product is called either gold filled or rolled gold plate. The weight ratio of alloyed gold to base metal varies from $1 / 10$ down to $1 / 500$, which latter is a very thin coating indeed, hardly comparable with a good gold electroplate.

47. In order to provide a definite quality mark for better understanding between buyers and sellers which could be enforced against the seller if necessary, the New England Manufacturing Jewelers' and Silversmiths' Association in 1933 proposed standard quality marks which included the ratio be weight of the gold alloy to the base metal and the karat fineness, for example, " $1 / 1012 \mathrm{~K}$ Gold Filled", with $10 \mathrm{~K}$ as the minimum fineness and $1 / 20$ the minimum weight ratio for items marked gold filled. As a result, the proposal was accepted with some adjustments and Commercial Standard CS47-34 was established for "Marking of Gold-Filled and Rolled-Gold-Plate Articles Other Than Watchcases."

48. In addition to the quality marks on the articles themselves, many items are accompanied by a card bearing a further voluntary declaration by the manufacturer as follows:

The Company guarantees this Gold Filled article to be marked for quality in strict accordance with the Commercial Standard CS47-34 as issued by the United States Department of Commerce, and approved by the American Standards Association.

49. Retailers, manufacturers, and consumer groups are all pleased with the many improvements brought about through the quality marks and guarantee cards based upon this standard. The noteworthy benefits have stimulated the establishment of three related 
standards for gold and silver combinations, platinum articles, and karat gold articles.

\section{BENEFITS AND SAVINGS}

50. No definite study has been undertaken to determine the exact savings resulting from standardization. Much of the savings are due to fundamental and more or less intangible benefits which build up from year to year. The savings usually reported are for comparatively short periods covering isolated cases and incompletely defined conditions making them difficult to analyze and correlate. An ever-increasing number of groups are heartily endorsing standardization and many have worked out extensive programs of their own. Their experience indicates that they benefit from standardization in one or more of the ways listed below. They also find that the benefits are increased by the wider use of standards. Since commercial standards signify Nation-wide application of essential standards or yardsticks for service characteristics, it seems reasonable to expect that such benefits are realized even more fully from commercial standards.

\section{FOR THE PRODUCER}

51. From the viewpoint of the producer, a commercial standard faithfully followed and supported by labeling-

\section{(a) AS REGARDS PRODUCTION}

(1) Reduces waste in manufacture through-

(a) Longer runs, less frequent change.

(b) Higher rates of individual production.

(c) More accurate estimating for production.

(d) More effective stock control.

(e) Better and simpler inspection.

(f) Less equipment.

(g) Fewer raw materials.

(h) Cheaper handling of stock.

(i) Closer cost accounting.

(j) Improvement of design.

(2) Improves relations with labor by-

(a) Higher earnings through increased individual production.

(b) More permanent employment.

(c) Easier training of new employees.

(3) Increases turnover.

(4) Lowers selling cost.

(b) AS REGARDS MARKETING

(5) Increase his confidence by-

(a) Providing an honest, straight-forward, openly-arrived-at, nationally recognized basis for daily trade.

(b) Setting minimum limits for one or more grades below which quality shall not be allowed to fall.

(c) Creating a better understianding between buyer and seller thus reducing possibilities for error and litigation.

(d) Reducing the variety of specifications for the commodity.

(e) Providing a fair basis for competition.

(f) Steadying demand.

(g) Reducing need for acceptance tests by customers.

(h) Providing sound basis for foreign trade.

(6) Establishes a thoroughly recognized basis for certification of quality. 
(7) Increases confidence and good will among customers due to-

(a) Certified quality of product.

(b) More prompt delivery.

(c) Reduced variety.

(d) Better quality of packing.

(e) More accurate labeling as to grade, type, class, and size.

(8) Provides facts which increase directness, forcefulness, and effectiveness of national advertising.

(9) Strengthens acceptance and good will for company brands.

(10) Forms a broad new basis for group advertising.

(11) Fosters and promotes self-government in business.

\section{FOR THE DISTRIBUTOR}

52. From the viewpoint of the wholesaler and retailer, a commercial standard-

(1) Provides factual basis for-
(a) Selection of stock.
(b) Advertising and selling.
(c) Adjustment of complaints.
(d) Protection of his reputation and prestige.

(2) Increases confidence and good will by the same means as listed under producer viewpoint above.

(3) Lowers stock investment through reduced variety.

(4) Increases turnover by-

(a) Greater concentration of stock and sales effort.

(b) Stabilizing demand.

(c) Reducing obsolescence and depreciation.

(5) Reduces overhead due to-
(a) Handling.
(b) Accounting.
(c) Shortened selling time.
(d) Minimized returns.

(6) Improves service by-

(a) Quicker deliveries.

(b) Easier replacement.

(c) Greater interchangeability.

(7) Stimulates trade by-

(a) Allowing for full play of initiative and individuality of style, pattern, finish, color, texture, etc.

(b) Encouraging ingenuity, diversity and change in those elements which appeal to the taste and personality of the individual buyer.

\section{FOR THE TESTING LABORATORY}

53. From the viewpoint of the testing laboratory, a commercial standard-

(1) Focuses attention on the efficacy of testing as a means of determining quality.

(2) Provides authoritative criteria and methods of test.

(3) Establishes recognized basis for certification procedure.

(4) Emphasizes need for check tests by independent agency.

\section{FOR THE CONSUMER}

54. From the viewpoint of the purchaser, a commercial standard-

(1) Gives greater confidence and assurance of quality and quantity.

(2) Provides a definite and legal basis for return or redress.

(3) Broadens fair competition.

(4) Provides better fitness and durability for a specific purpose.

(5) Insures easy replacement.

(6) Provides greater interchangeability.

(7) Permits earlier deliveries and better service. 
(8) Lowers costs as measured by value.

(9) Reduces inspection costs.

(10) Provides recognized basis for comparison of values.

(11) Shortens buying time.

\section{SUMMARIZING ALL VIEWPOINTS}

55. A simplified line, certified and labeled according to a commercial standard for grade and quality, propagated by national advertising, should represent a maximum of practicable protection to the consumer, promote greater confidence and provide a reliable source of profit and good will to the manufacturer and distributor.

\section{QUESTIONS AND ANSWERS}

\section{ESSENTIALS OF COMMERCIAL STANDARDS}

\section{Question 1. What is a commercial standard?}

ANSwER. A commercial standard, promulgated by the National Bureau of Standards, is a voluntary, recorded standard agreed upon by producers, distributors, and consumers, covering terminology, types, classifications, grades, sizes, and use characteristics of manufactured products as a basis for better understanding between buyer and seller. It includes standard methods of test, rating, certification, and labeling, and provides a uniform basis for fair competition.

Question 2. What are the primary functions of the Division of Trade

Standards?

ANSwer. See paragraph 15, page 4.

Question 3. Who may request commercial standards?

ANSwER. Any interested group of consumers, producers, or distributors may request the cooperation of the National Bureau of Standards in establishing commercial standards.

Question 4. What is expected of the proponent group requesting such service?

ANswer. The proponent group and its members are expected to be interested sufficiently to answer questions, supply data, prepare tentative draft of recommendation, give advice based on experience, and to attend a few meetings, as required, at their own expense.

Question 5. Does the establishment of a commercial standard involve any fee?

ANSWER. No charge is made for establishing commercial standards, since they serve producers, distributors, and consumers alike.

\section{COMPARISON WITH OTHER STANDARDS}

Question 6. What is the essential difference between commercial standards and specifications adopted by engineering and technical societies?

ANSWER. The usual specification covers purchase requirements for contract buyers with little or no concern for what may happen to rejected items or goods outside the limits of the specification. Commercial standards on the contrary are established to serve not only as a basis for purchase, but more especially as a basis for marketing, and consequently must reflect all of the grades necessary in that industry, or form a part of a broader plan for marketing the essential grades, 
both standard and substandard. Frequently, after group consideration of the entire field, it will be found best to convert or divert the substandard goods into other goods or channels. Thus commercial standards, unlike most specifications, are established for the benefit of all parties interested in a given commodity rather than for a certain group.

Question 7. How do commerical standards differ from Federal specifications?

ANSwER. Federal specifications are prepared by committees of Government experts as a basis for official Federal purchases, whereas commercial standards are voluntarily formulated and accepted as a basis for daily trade. They may be consistent with one another but are not necessarily so.

Question 8. Are commercial standards likely to bring about similar requirements in Federal or purchase specifications?

ANswer. Yes. The most difficult part of the preparation of Federal or other purchase specifications is to obtain an authoritative statement of the current practices and grades produced by the industry as a whole. The commercial standard adequately fills this need and makes it unnecessary to prepare an individual specification for material conforming to the commercial standard. The tendency of the specification writer is at once to adopt the nationally recognized specification for daily trade- the commercial standard.

Question 9. Are commercial standards used as a basis for Federal purchases in cases where there is no Federal specification?

ANswer. Yes. Section III (part 6) of the Federal Standard Stock Catalogue invites attention to commercial standards and recommends their use in these words, "In order that the Government may lend its full support to this valuable movement, and, at the same time, enjoy its benefits, it is recommended that heads of departments and establishments issue appropriate instructions to ensure acceptance of Commercial Standards whenever feasible and to require the purchase of materials and supplies, not covered by Federal Specifications, in conformity with the Commercial Standards, except when such action would be prejudicial to the Government's interests."

Question 10. How do commercial standards differ from simplified practice recommendations?

ANSwER. In general, it may be said that a simplified practice recommendation covers types, sizes, and varieties of a commodity which are retained by industry on the basis of demand, whereas a commercial standard establishes definite requirements as to grade, quality, or dimensional tolerances in addition to any limitation of variety desired and accepted by all concerned.

\section{BENEFITS}

Question 11. What benefits may we expect to receive from the establishment of a commercial standard?

ANswer. For benefits to the producer, distributor, testing laboratory, and consumer, see pages 16,17 , and 18 .

Question 12. Will the commercial standard save me any money as a consumer?

Answer. Decidedly yes. Frequently there will be no immediate reduction in price, though this may be brought about gradually 
through greater competition. Immediate savings, particularly on small deliveries, are brought about through improved quality or performance, and the assurance by the manufacturer or an independent testing laboratory that the goods delivered are up to the specification standard. Price should not be confused with cost, which, to the consumer, means the expenditure for net performance or utility per unit of time or service.

\section{PROCEDURE}

Question 13. Is the procedure for establishing commercial standards difficult or involved?

ANSWER. No; it is really quite simple; see figure 2.

Question 14. What should we do first?

ANSWER. State your particular difficulties by letter or call at the Bureau and discuss them with the division of trade standards.

Question 15. Must the request take any official or special form?

ANSWER. No. Simply request our cooperation or assistance in your own words.

Question 16. Does our organization have to assume responsibility for complying with the various requirements of the procedure?

ANSwer. No. Simply ask for cooperation and the National Bureau of Standards will guide the procedure.

Question 17. Our industry needs standards, but where should we begin?

ANSWER. Examine your trade terms for the various grades; write specific definitions for each as a uniform guide to all interested parties. Question 18. Are related technical and commercial organizations and testing laboratories consulted?

ANSwER. They are invited to criticize the proposed commercial standard while still in tentative form, to attend the general conference, and cooperate in modifying the draft to suit all elements directly concerned.

Question 19. How is an existing association specification converted into a commercial standard?

ANSWER. The association may submit such specification or standard for approval as a commercial standard, whereupon it will be subjected to the usual scrutiny, such adjustments as are necessary, and to such elements of the regular procedure as may be required.

Question 20. How long does it take?

ANSWER. The time required depends upon the cooperation rendered by the proponents and the previous status of the specification. Certain projects have been adopted by the general conference in less than 3 months from the date of the original request. Procurement of written acceptances frequently requires 2 to 3 months or more after the general conference. Publication within 10 months or 1 year from the inception of the project may be regarded as good time, considering the fundamental character and significance of such an undertaking.

\section{ACCEPTANCE}

Question 21. What is the form of acceptance each producer, distributor, and consumer is asked to sign?

ANSWER. The exact form of acceptance is given on page 9 . 
Question 22. Does my signature on the acceptance blank strictly limit my purchases or sales to the commercial standard grades?

ANSWER. No. You are entering an entirely voluntary arrangement whereby all concerned will encourage, by all sensible means, the use of standard grades and qualities for mutual benefit and protection. It is realized that instances will occur in which it will be necessary to buy, supply, or introduce nonstandard items. The commercial standard is not intended in any way to stifle initiative or ingenuity in the betterment of any commodity nor to interfere in the orderly conduct of commerce, but it should act as a ratchet to catch and to hold for all time the progress and efficiency already achieved.

\section{PUBLICATION}

Question 23. What are the minimum conditions under which the National Bureau of Standards will print a commercial standard?

ANSWER. At least 65 percent of production or consumption by volume must be represented by signed acceptances, with no outstanding or organized active, valid opposition from any quarter, before a commercial standard is printed. The percentage is set purposely low to allow for that portion of the industry which may be apathetic or which may wish to wait for a trial of the commercial standard without in any way opposing it. Since trade associations usually have no authority to bind members to any action, acceptances from associations are not counted in determining the proportion of production represented by acceptances.

Question 24. How many pamphlets are printed for free distribution?

ANswer. Usually about 2,500 copies are printed for official use and for free distribution.

Question 25. Can additional copies be obtained for further distribution by the industry?

ANswer. Yes. Trade associations and individual companies often distribute large numbers of the printed standard for the information and guidance of their members or customers. Additional copies may be obtained in quantities of 100 or more at a discount of 25 percent from the Superintendent of Documents, U. S. Government Printing Office, Washington, D. C.

\section{LABELING}

Question 26. Can we refer to the Government publication on our guarantee labels?

ANswer. Producers are encouraged to make a specific and complete reference to the Government publication on all labels, tags, cartons, and sales literature certifying quality as conforming to the commercial standard requirements.

Question 27. Do you expect ultimate consumers to become familiar with the requirements of all these standards?

ANswer. No. It is expected, however, that with the cooperation of associations of purchasing agents, women's clubs, and other consumer group organizations, the buyers will prefer goods bearing self-certifying labels guaranteeing a quality equal to or exceeding the commercial standard grade. 


\section{ADHERENCE AND POLICING}

Question 28. Does the National Bureau of Standards prepare lists of "willing-to-certify" manufacturers?

ANSwER. Yes. Upon request of the general conference the Bureau compiles and distributes lists of manufacturers who are willing, when requested to do so, to certify to purchasers that products supplied by them comply with all the requirements and tests set forth in nationally recognized commercial standards. These lists are available on request to individual consumers, consumer groups, companies, and in fact to any prospective purchasers, for their guidance.

Question 29. How is conformity to the commercial standard policed in cases of willful departure?

ANswer. The National Bureau of Standards has no police powers in connection with commercial standards. It desires none, and hence, such policing as may be necessary is done by the industry itself through trade association action and moral suasion. It is expected that goods sold merely on a price basis will be made conspicuous by the absence of the quality guarantee or self-certifying label and thus put the purchaser on his guard.

Question 30. Is there any legal redress against the producer who willfully sells substandard goods under a written guarantee or under a self-certifying label as conforming to the commercial standard?

ANswer. Yes. It constitutes a breach of the sales contract and, therefore, may serve as a basis for legal action to recover damages. It may likewise serve as a basis for corrective action through the Federal Trade Commission as an unfair method of competition or as deceptive to the purchaser. Or action may be taken under the various State laws for the prevention of misrepresentation.

\section{REVISION}

Question 31. How do you provide for revisions?

ANSWER. Provision for regular revision is made by the appointment of a standing committee to consider periodically any necessity for revision or extension of the commercial standard, in order that it may be kept constantly compatible with progress in the art.

Question 32. How frequently are commercial standards revised?

ANSWER. The necessity for revision is usually considered once a year, or more frequently if required.

\section{FOREIGN TRADE PROMOTION}

Question 33. How can commercial standards be used to stimulate foreign commerce?

ANSwER. Through the cooperation of the Bureau of Foreign and Domestic Commerce, commercial standards may be published in foreign languages by the Federal Government and circulated abroad through our foreign trade representatives as a proffered basis for foreign trade, or related standards particularly suited to the export trade may be established. 


\section{COMMERCIAL STANDARDS}

CS No.

Item

0-40. Commercial standards an business (third edition).

1-32. Clinical thermometers (second edition). 2-30. Mopsticks.

3-38. Stoddard solvient (second edition).

4-29. Staple porcelain (all-clay) plumbing fixtures.

5-29. Steel pipe nipples.

6-31. Wrought-iron pipe nipples (second edition).

7-29. Standard weight malleable iron or stee screwed unions.

8-33. Gage blanks (second edition).

9-33. Builders' template hardware (second edition).

10-29. Brass pipe nipples.

11-29. Regain of mercerized cotton yarns.

12-40. Fuel oils (fifth edition)

13-39. Dress patterns (second edition).

14-39. Boys' button-on waists, shirts, junior and polo shirts (made from woven fabrics) (second edition).

15-29. Men's pajamas.

16-29. Wall paper.

17-32. Diamond core drill fittings (second edition).

18-29. Hickory golf shafts.

19-32. Foundry patterns of w,ood (second edition).

20-36. Staple vitreous china plumbing fixtures (second edition).

21-39. Interchangeable ground-glass joints, stopcocks, and stoppers (fourth edition).

22-30. Builders' hardware (nontemplate).

23-30. Feldspar.

24-30. Standard screw threads.

25-30. Special screw threads.

26-30. Aromatic red cedar closet lining.

27-36. Mirrors (second edition).

28-32. Cotton fabric tents, tarpaulins, and covers.

29-31. Staple seats for water-closet bowls.

$30-31$. Colors for sanitary ware.

31-38. Wood shingles (fourth edition)

$32-31$. Cotton cloth for rubber and pyroxylin coating.

33-32. Knit underwear (exclusive of rayon).

34-31. Bag, case, and strap leather.

35-31. Plywood (hardwood and eastern red cedar).

36-33. Fourdrinier wire cloth (second edition).

37-31. Steel bone plates and screws.

38-32. Hospital rubber sheeting.

39-37. Wool and part wool blankets (second edition).

40-32. Surgeons' rubber gloves.

41-32. Surgeons' latex gloves.

42-35. Fiber insulating board (second edition).

43-32. Grading of sulphonated oils.
CS No.

44-32. Apple wraps.

45-38. Douglas fir plywood (domestic grades) (third edition).

46-36. Hosiery lengths and sizes (second edition).

47-34. Marking of gold-filled and rolled-gold-plate articles other than watch cases.

48-34. Domestic burners for Pennsylvania anthracite (underfeed type).

49-34. Chip board, laminated chip board, and miscellaneous boards for bookbinding purposes.

50-34. Binders board for bookbinding and other purposes.

51-35. Marking articles made of silver in combination with gold.

52-35. Mohair pile fabries (100-percent mohair plain velvet, 100-percent mohair plain frieze, and 50-percent mohair plain frieze).

53-35. Colors and finishes for cast stone.

54-35. Mattresses for hospitals.

55-35. Mattresses for institutions.

56-36. Oak flooring.

57-36. Book cloths, buckrams, and impregnated fabrics for bookbinding purposes except library bindings.

58-36. Woven elastic fabrics for use in overalls (overall elastic webbing).

59-39. Woven dress fabrics-testing and reporting (second edition).

60-36. Hardwood dimension lumber.

61-37. Wood-slat venetian blinds.

62-38. Colors for kitchen accessories.

63-39. Colors for bathroom accessories.

64-37. Walnut veneers.

65-38. Wool and part-wool fabrics.

$66-38$. Marking of articles made wholly or in part of platinum.

67-38. Marking articles made of karat gold.

68-38. Liquid hypochlorite disinfectant, deodorant, and germicide.

69-38. Pine oil disinfectant.

70-38. Coal tar disinfectant (emulsifying type).

71-38. Cresylic disinfectants.

72-38. Household insecticide (liquid spray type).

73-38. Old growth Douglas fir standard stock doors.

74-39. Solid hardwood wall paneling.

75-39. Automatic mechanical draft oil burners.

76-39. Hardwoodinterior trim and molding.

77-40. Sanitary cast iron enameled ware.

78-39. Ground-and-polished lenses for sun glasses.

79-39. Blown, drawn, and dropped lenses for sun glasses.

Notice.-Those interested in commercial standards with a view toward accepting them as a basis of everyday practice may secure copies of the above standards, while the supply lasts, by addressing the Division of Trade Standards, National Bureau of Standards, Washington, D. C. 
